\title{
Sensory Integration and Standing Balance in Adolescent Taekwondo Practitioners
}

\author{
Shirley S.M. Fong and Gabriel Y.F. Ng \\ Hong Kong Polytechnic University
}

\begin{abstract}
Taekwondo (TKD) is a popular sport among adolescents. This study aims to (a) compare the balance performance between adolescent TKD practitioners at different levels of expertise with nonpractitioners and (b) determine the sensory system(s) that contributed to the balance function in adolescents with and without TKD training. Subjects with $>5$ years of TKD training $(n=11),<4$ years of training $(n=10)$, and no training $(n=10)$ participated in this study. The sway velocity, somatosensory, vestibular and visual ratios were recorded during standing on a balance testing system. Both short- and long-term TKD practitioners swayed slower than control subjects when standing on one leg ( $p=.016$ and 0.012 , respectively). However, only short-term practitioners have better visual ratio $(p=.018)$ and vestibular ratio $(p=.029)$ than control subjects. There was no significant difference in the somatosensory ratio among the 3 groups. We conclude that adolescents undertaking TKD training may have better balance performance than untrained subjects.
\end{abstract}

Taekwondo (TKD) is an Olympic sport and a popular martial art among children and adolescents (17). Despite its combative nature, it is relatively safe because protective gears are mandatory and practitioners must follow strict rules during competitions. According to Pieter, concussion injuries ranged between $5 \%$ and $8.8 \%$ of all injuries in young male TKD practitioners whereas for females, it ranged between $8.1 \%$ and $9.6 \%$. This injury rate was slightly higher than that reported in Judo and karate practitioners. However, more serious injuries like joint dislocation in young TKD practitioners were far lower than those of other martial arts (21).

TKD is renowned for its swift kicking techniques and practitioners have many opportunities to stand on one leg during training and sparring (22). Therefore, unilateral stance stability is crucial for TKD practitioners. The ability in balance and postural control is a determining factor for the athletes' performance in competitions but there have been very few studies investigating the effect of TKD training on balance control. Brudnak and colleagues were the first group that reported a beneficial effect of TKD training on single leg standing balance in the elderly population.

Fong and Ng are with the Dept. of Rehabilitation Sciences, Hong Kong Polytechnic University, Hong Kong (SAR), China. 
They found an improvement in standing balance time on each leg after 17 weeks of TKD training (3). However, the major limitation of that study was the lack of a control group due to the dropping out of all the control subjects after the study had started and the data were not statistically analyzed. So their conclusion should be interpreted with caution. Later, Cromwell et al. studied the effect of TKD training on balance and walking ability in older adults and found that the subjects' multidirectional reaching ability, gait stability and walking velocity had more significant improvements after 11 weeks of training than the control group that did not receive any training. They concluded that TKD was effective for improving balance and walking ability in community-dwelling elderly (4). However, the authors did not report any interaction effect between the 2 independent variables and did not take the possible confounding factors (e.g., health status) into account.

Hitherto, the scientific evidence on the effect of TKD training on functional balance is patchy and inconclusive. Most previous studies have only focused on the adult population. In light of the increasing popularity of this sport and majority of its practitioners start training at a very young age (17), there is a need to examine the effect of TKD training on balance in younger population.

The ability for one to maintain balance is dependent on the function of the central nervous system (CNS) in selecting and integrating accurate sensory inputs from the visual, vestibular and somatosensory systems (14). The use of various sensory information is needed because different types of balance disturbances stimulate different sensors and the sensitivity range of each sensor also varies. When one or more of the systems provide misleading information to the CNS, inputs from the other systems might be able to compensate (14). It has been reported that training in sport activities could enhance the choice of an appropriate sensory cue for balance in young people (12). Sportsmen would select the most appropriate information from the sensory systems to maintain posture according to the requirements of their sports. Therefore, it has been well reported that sports training could induce the development of specific postural control strategies $(1,2,8,9,11,13,19,20)$. For example, gymnasts and dancers use somatosensory inputs more than otholitic cues or visual cues for perception of body orientation and balance $(2,11)$. Judoists rely heavily on proprioceptive senses to adjust their posture and maintain balance during competitions (19). Ironmen are less dependent on vision than normal active subjects (13). Shooters and fencers use proprioceptive and vestibular cues more than vision to stabilize posture and save the visual sense to focus on sports related events (9). Synchronized ice skaters depend on the vestibular system to fine tune body posture (1).

Despite the popularity of TKD, no study has investigated the sensorimotor specificities in young TKD practitioners. Therefore, this study aims to: (a) compare the balance performance in adolescent TKD practitioners at different levels of expertise with nonpractitioners, and (b) determine the sensory system(s) that contributed to the balance function in adolescents with and without TKD training. We hypothesized that TKD practitioners have better balance ability and can develop specific sensory integration specific to the combative kicking nature of TKD. Findings of this study might provide the evidence of and insight for designing specific balance exercises for young adolescents to enhance their sensory integration and balance ability. 


\section{Methods}

\section{Subjects}

31 subjects (19 boys and 12 girls, 11-14 years old) volunteered for this study. 11 were long-term TKD practitioners with 5-9 years of TKD experience and black belt qualified. 10 subjects were short-term TKD practitioners with 1-4 years of TKD experience and not black belt qualified (Table 1). All TKD subjects were trained for a minimum of $4 \mathrm{hr}$ per week. The other 10 were normal control subjects without previous experience in TKD or other martial arts. The exclusion criteria were the presence of vestibular or visual disorders, musculoskeletal or neurological diseases, history of injury in the past 12 months requiring medical attention and regular training in sports other than TKD. The study was approved by the human subjects ethics review subcommittee of the Hong Kong Polytechnic University. The procedures were fully explained to the subjects and their parents, who gave their written consents before testing. All procedures of this study were performed in accordance with the Declaration of Helsinki.

\section{Unilateral Stance Test (UST)}

The subjects took a single leg standing balance test with a Computerized Dynamic Posturography machine (NeuroCom International Inc., Smart Equitest system) by barefoot standing with their nondominant leg on the machine for $10 \mathrm{~s}$. During the test, a standardized posture was adopted with arms by the side of trunk, eyes looking forward and the hip of the supporting leg flexed at $45^{\circ}$ so as to resemble the starting position of front kick in TKD practice. The sway velocity of the center of gravity (COG) was recorded by the machine (15). Three trials were performed with a 10-s rest in between. The mean COG sway velocity across the 3 trials was obtained and then used for analysis.

Table 1 Comparison of Age, Height, Body Weight and Gender Between Long-Term, Short-Term TKD Practitioners and Control Subjects

\begin{tabular}{lcccc}
\hline & $\begin{array}{c}\text { Long-term TKD } \\
\text { group }(\mathbf{N}=11)\end{array}$ & $\begin{array}{c}\text { Short-term TKD } \\
\text { group }(\mathbf{N}=10)\end{array}$ & $\begin{array}{c}\text { Control group } \\
(\mathbf{N}=10)\end{array}$ & $\begin{array}{c}\mathbf{P} \\
\text { value }\end{array}$ \\
\hline $\begin{array}{l}\text { Mean age } \pm S D \\
\text { (range) (year) }\end{array}$ & $13.4 \pm 0.8(12-14)$ & $12.9 \pm 1.2(11-14)$ & $12.3 \pm 1.3(11-14)$ & 0.102 \\
$\begin{array}{l}\text { Mean height } \pm \\
S D(\mathrm{~cm})\end{array}$ & $156.4 \pm 7.3$ & $155.6 \pm 11.8$ & $149.6 \pm 10.2$ & 0.254 \\
$\begin{array}{l}\text { Mean body } \\
\text { weight } \pm S D(\mathrm{~kg})\end{array}$ & $49.2 \pm 8.5$ & $47.3 \pm 13.4$ & $46.5 \pm 9.0$ & 0.830 \\
$\begin{array}{l}\text { Gender (male, } \\
\text { female })\end{array}$ & $7 \mathrm{M}, 4 \mathrm{~F}$ & $6 \mathrm{M}, 4 \mathrm{~F}$ & $6 \mathrm{M}, 4 \mathrm{~F}$ & \\
\hline
\end{tabular}

Abbreviations: M, male; F, female 


\section{Sensory Organization Test (SOT)}

After the UST, postural sway was assessed in bipedal stance under reduced or conflicting sensory conditions with the sensory organization test. The SOT is commonly used to evaluate the subject's ability to make effective use of visual, vestibular and somatosensory inputs separately and filter out inappropriate sensory information when they are maintaining balance.

Subjects stood with bare feet on the platform of the Computerized Dynamic Posturography machine (NeuroCom International Inc., Smart Equitest system). They wore a security harness to prevent fall. All subjects were asked to stand still with arms resting on both sides of the trunk and eyes looking forward. During the test, subjects were exposed to 6 different combinations of visual and support surface conditions (Table 2).

Subjects were asked to ignore any motion in the supporting surface or visual surround and remain in an upright position as steadily as possible for $20 \mathrm{~s}$. If the subjects took a step or required assistance of the harness, the trial was rated as a fall (15). Each subject was tested for 3 times in each condition.

The machine detected the trajectory of the center of pressure (COP) of the subject which was then used to calculate the equilibrium score (ES) (14). Equilibrium score was defined as the nondimensional percentage which compared the subject's peak amplitude of antero-posterior (AP) sway to the theoretical limits of antero-posterior stability $\left(12.5^{\circ}\right)$. The theoretical limit of stability was influenced by the individual's height and size of the supporting base. It represented an angle $\left(8.5^{\circ}\right.$ anteriorly and $4.0^{\circ}$ posteriorly) at which the person could lean in any direction before the center of gravity would move beyond the point of falling.

The equilibrium score was calculated by the NeuroCom software with the formula:

$$
\left.12.5^{\circ}-\left(\left(\theta_{\max }-\theta_{\min }\right) / 12.5^{\circ}\right) \times 100 \quad \text { (Equation } 1\right)
$$

Where $\mathrm{q}_{\max }$ is the greatest AP COG sway angle attained by the subject and $\mathrm{q}_{\min }$ is the lowest AP COG sway angle. An ES of 100 represented no sway (excellent balance control), whereas 0 indicated a sway exceeding the limit of stability, resulting in a fall $(9,14)$. After obtaining the ES, the mean equilibrium scores of each testing condition across the 3 trials were calculated and these averaged scores were used to calculate the somatosensory, visual and vestibular ratios (Table 3). These three

\section{Table 2 The Six Testing Conditions of the Sensory Organization Test}

\begin{tabular}{ll}
\hline Testing condition & Description \\
\hline 1 & Eyes open, fixed support \\
2 & Eyes closed, fixed support \\
3 & Sway-referenced* vision, fixed support \\
4 & Eyes open, sway-referenced* support \\
5 & Eyes closed, sway-referenced* support \\
6 & Sway-referenced* vision and support \\
\hline
\end{tabular}

*Sway-referenced - tilting of support surface and /or the visual surround about an axis colinear with the ankle joints to directly follow the anterior-posterior sways of the subject's center of gravity (15). 


\section{Table 3 Sensory Analysis Ratios and Their Functional Relevance}

\begin{tabular}{|c|c|c|}
\hline Sensory ratio* & Computation & Functional relevance \\
\hline $\begin{array}{l}\text { Somatosensory } \\
\text { ratio }\end{array}$ & $\begin{array}{l}\text { ES of condition } 2 / \\
\text { ES of condition } 1\end{array}$ & $\begin{array}{l}\text { Subject's ability to use input from the } \\
\text { somatosensory system to maintain balance. }\end{array}$ \\
\hline Visual ratio & $\begin{array}{l}\text { ES of condition } 4 \text { / } \\
\text { ES of condition } 1\end{array}$ & $\begin{array}{l}\text { Subject's ability to use input from the visual } \\
\text { system to maintain balance. }\end{array}$ \\
\hline Vestibular ratio & $\begin{array}{l}\text { ES of condition } 5 / \\
\text { ES of condition } 1\end{array}$ & $\begin{array}{l}\text { Subject's ability to use input from the ves- } \\
\text { tibular system to maintain balance. }\end{array}$ \\
\hline
\end{tabular}

Abbreviations: ES, Three-trial average equilibrium score.

*The sensory ratios were generated automatically by the SMART BalanceMaster system $(14,15)$.

sensory ratios were then used to identify the significance of each sensory system in balance control. High sensory ratio of close to 1 reflected the subject had superior ability to rely on that particular sensory system for balance (14).

\section{Statistical Analysis}

Intraclass correlation coefficient model 3, $1\left(\mathrm{ICC}_{3,1}\right)$ was calculated to assess the test-retest reliability of the unilateral stance test and sensory organization test in young adolescents. Each outcome was tested 3 times with 25 normal subjects who were not involved in the main study. The absolute values of COG sway velocity and SOT equilibrium scores for conditions 1-6 in the 3 trials were used to calculate the ICC values.

SPSS version 17.0 was employed for all statistical analyses. The level of significance was set at 0.05 . Normality of data were first checked with Shapiro-Wilk tests. One-way ANOVA was used to compare the age, height and body weight among the 3 groups. For between-group comparisons of the 4 outcomes, namely, COG sway velocity, somatosensory ratio, visual ratio, and vestibular ratio, one-way ANOVA was performed. Significant results were further analyzed with post hoc Bonferroni multiple comparisons. Cohen's d, which is the standardized measure of effect size between 2 groups, was also presented for each primary outcome. By convention, Cohen's d values of $0.20,0.50$, and 0.80 are considered to be small, medium, and large, respectively (23).

\section{Results}

The ICC value for the COG sway velocity was 0.77 which indicated a good reliability for the unilateral stance test. The ICC values for the equilibrium scores of SOT conditions 1-6 ranged from 0.50 to 0.77 which indicated moderate to good reliability for the SOT.

Between-group comparisons revealed no significant difference in age, height, body weight and gender among the 3 groups (Table 1). In addition, the numbers of male and female participants were similar across the 3 groups. Univariate tests revealed significant differences in visual ratio, vestibular ratio and COG sway velocity, but not the somatosensory ratio among the 3 groups (Table 4). 


\section{Table 4 Comparison of Balance Control Under Different Sensory Conditions and the COG Sway Velocity in Single Leg Standing Among Long-Term, Short-Term TKD, and Control Subjects}

\begin{tabular}{lccccc}
\hline Sensory ratio & $\begin{array}{c}\text { Long-term } \\
\text { TKD subjects }\end{array}$ & $\begin{array}{c}\text { Short-term } \\
\text { TKD subjects }\end{array}$ & $\begin{array}{c}\text { Control } \\
\text { subjects }\end{array}$ & $\begin{array}{c}\text { Effect } \\
\text { size (f) }\end{array}$ & P value \\
\hline $\begin{array}{l}\text { Somatosensory } \\
\text { ratio }\end{array}$ & $0.98 \pm 0.03$ & $0.99 \pm 0.02$ & $0.97 \pm 0.02$ & 0.40 & 0.476 \\
Visual ratio & $0.81 \pm 0.11$ & $0.90 \pm 0.05$ & $0.80 \pm 0.05$ & 2.22 & $* 0.011$ \\
Vestibular ratio & $0.57 \pm 0.17$ & $0.67 \pm 0.09$ & $0.46 \pm 0.23$ & 4.22 & $* 0.033$ \\
$\begin{array}{l}\text { COG sway velo- } \\
\text { city in UST }\end{array}$ & $1.01 \pm 0.14$ & $1.02 \pm 0.22$ & $1.58 \pm 0.68$ & 13.21 & $* 0.006$ \\
\hline
\end{tabular}

*Denotes significant difference at $\mathrm{p}<0.05$ among the 3 groups by using univariate tests.

Post hoc analyses revealed that both short-term and long-term TKD practitioners had swayed significantly slower than the control subjects during single stance with eyes open. The COG sway velocity in long-term TKD practitioners was $36 \%$ less than the controls while the COG sway velocity in short-term TKD practitioners was $35.4 \%$ less than the controls. However, only short-term TKD practitioners had better visual ratio than the control subjects and they even outperformed the longterm TKD practitioners. The short-term TKD practitioners also had better vestibular ratio than the control subjects. However, there was no significant difference in the somatosensory ratio among the 3 groups and the effect sizes for the different group comparisons ranged from 0.39 (medium) to 1 (large; Table 5).

\section{Discussion}

The present study revealed that both short-term and long-term TKD practitioners had significantly slower body sway than the control subjects during nondominant leg standing. The superior upright unilateral stance stability in the young TKD subjects may result from the repeated practice of high kicks during training. According to the competition rules, kicks to the head would score more points than the trunk and fast offensive kicks have accounted for more than half of the techniques used to score points during TKD competitions (10). Practicing high kicks would require high level of balance thus improve the postural regulation in unilateral stance (16).

Del Percio et al. studied the neuro-physiological mechanisms of improved standing balance in elite karate (a martial sport similar to TKD) athletes and suggested that practice of frequent kicking to a mobile visuo-spatial target enabled the athletes to cope with highly demanding visual-somatosensory-vestibular integration. Cerebral mechanisms for integrating the visual, somatosensory and vestibular inputs might become more effective with prolonged training and result in less body sway in standing (6). Furthermore, Perrin et al. proposed that athletes of combat sports could improve adaptive postural control with the skills acquired in training (18). TKD practitioners might develop better postural adjustment strategies and body alignment during kicking and blocking which would all improve body balance (28). 
Table 5 Effect Sizes and P Values for the Pairwise Comparisons

\begin{tabular}{|c|c|c|c|c|c|c|}
\hline & \multicolumn{2}{|c|}{$\begin{array}{l}\text { Long-term Vs short- } \\
\text { term TKD subjects }\end{array}$} & \multicolumn{2}{|c|}{$\begin{array}{l}\text { Long-term TKD Vs } \\
\text { control subjects }\end{array}$} & \multicolumn{2}{|c|}{$\begin{array}{l}\text { Short-term TKD Vs } \\
\text { control subjects }\end{array}$} \\
\hline & $\begin{array}{l}\text { Effect } \\
\text { size (d) }\end{array}$ & $P$ value & $\begin{array}{l}\text { Effect } \\
\text { size (d) }\end{array}$ & $P$ value & $\begin{array}{l}\text { Effect } \\
\text { size (d) }\end{array}$ & $P$ value \\
\hline $\begin{array}{l}\text { Somatosensory } \\
\text { ratio }\end{array}$ & 0.39 & 1.000 & 0.39 & 1.000 & 1.00 & 0.683 \\
\hline Visual ratio & 1.05 & $* 0.036$ & 0.12 & 1.000 & 2.00 & $* 0.018$ \\
\hline Vestibular ratio & 0.74 & 0.587 & 0.54 & 0.419 & 1.20 & $* 0.029$ \\
\hline $\begin{array}{l}\text { COG sway } \\
\text { velocity in UST }\end{array}$ & 0.05 & 1.000 & 1.16 & $* 0.012$ & 1.11 & $* 0.016$ \\
\hline
\end{tabular}

*Denotes significant difference at $\mathrm{p}<0.05$

These could explain the phenomenon that TKD subjects swayed less in unilateral stance test than the control subjects.

\section{TKD Training and Visual Function}

The contribution of vision to balance has been well documented (14). The current study revealed that short-term TKD practitioners had significantly better visual ratio in the SOT than long-term TKD practitioners and control subjects. This implies that short-term TKD practitioners relied more on visual input to balance than long-term practitioners and control subjects.

Vision is important for orientating the body parts in space during form practice (8). Through TKD training, subjects could develop superior attention focus on changing visual cues. It has been suggested that athletes in combat sports such as karate and fencing would maximize the changing visual information to maintain upright standing (5). It is possible that this change also happens in TKD practitioners.

However, our results revealed that long-term TKD practitioners had less reliance on visual input for balance than short-term practitioners. This is in agreement with the reports by many researchers who studied balance ability in athletes of different sports $(2,8,12,16,20)$. For example, Perrot and his team found that balance control improved and the influence of visual input decreased with increasing level of expertise in Karate and French boxing athletes (20). Paillard et al. reported that nonprofessional soccer players were more dependent on vision for balance than players of the national team. The authors hypothesized that the elite players had better internal postural representations thus saving the vision for the information that emanated from the game (16). Bringoux et al. also postulated that prolonged intensive gymnastics training would develop a more complete and precise internal model of verticality (2). Furthermore, it has also been reported that professional dancers had higher accuracy of proprioceptive inputs and they would shift the sensorimotor dominance from vision to proprioception $(8,12)$.

Vecchio et al. explained the phenomenon of decreased visual reliance with increasing sports experience from the neuro-physiological perspective that visual 
information would affect the cortico-muscular coherence in upright standing in untrained subjects and amateur karate practitioners only, but not in elite practitioners. In elite athletes, long-term training could sharpen the proprioceptive and tactile sensory routes and these would contribute to postural stability thus reducing the reliance on visual sense (27).

The ability to balance on one leg is an essential skill of experienced TKD athletes so that during competition, they can spare their visual attention to their opponents' actions and find opportunities to attack. Thus, postural control might become subconscious in advanced practitioners. Less reliance on visual input for balance could also prevent over dependence on a sensor that relay external cues only (9). This would enable the TKD practitioners to balance effectively in a moving visual surround such as during turning or spinning kicks.

\section{TKD Training and Somatosensory Function}

Previous studies suggested that proprioception could be improved by sports training $(8,11,19,28)$. For example, elite soccer players and dancers had improved proprioceptive capacities and shifted the sensorimotor dominance from vision to proprioception for postural adjustment (8). Judo training would improve proprioception in dynamic situations (19) similar to gymnastics training on knee and ankle joint proprioception (11). School boys trained in karate had demonstrated larger improvements in standing balance with eyes closed than eyes open and this suggested that proprioception had improved with karate training (28).

Contrary to the above findings, the current study demonstrated that the somatosensory ratios in both TKD groups were similar to the control group. This could be due to the inadequate number of subjects thus compromising the statistical power. In fact, the effect size between short-term TKD group and control group was large (Table 5) which is suggestive that short-term TKD practitioners might have better somatosensory function than nonpractitioners. Further study should include more subjects to confirm this finding.

\section{TKD Training and Vestibular Function}

The present study revealed that short-term TKD practitioners relied more on vestibular input for balance than control subjects. In light that TKD training involves acrobatic jump kicks and spinning kicks, these would stimulate the vestibular system and might increase its sensitivity (26). The vestibular system is the most reliable sensor, especially in challenging conditions, because it does not rely on external references for postural control. Rather, it measures gravitational, linear and angular accelerations of the head in relation to inertial space or gravity (14). Therefore, a sensitive vestibular system would enable the TKD practitioners to maintain stability in challenging conditions such as performing spinning kicks on mattress.

Apart from being an organ for balance, the vestibular system also transmits information that triggers the vestibulo-ocular reflex which is important for stabilizing the visual images on the retina during head and body movements by rotating the eyes in an opposite direction to head movement. Therefore, with a sensitive vestibular system, the short-term TKD practitioners could also use vision to enhance balance during movements (26). 


\section{Limitations and Suggestions for Future Studies}

There were some limitations in this study that need to be considered when interpreting the findings. First, the current study shows a relationship between TKD experience and postural ability but whether this relationship is influenced by the amount of training or natural predispositions is not known. This would best be tested by a longitudinal study. Second, the number of subjects in this study was small. Further study should include more participants to differentiate the balance and sensory abilities between TKD practitioners and nonpractitioners. Third, more studies are needed to confirm which sensory/motor system(s) had contributed to the better single leg standing balance in the long-term TKD practitioners. Finally, maturity of the participants and the age at which they started TKD training should also be considered in future studies as they may have an effect on the balance performance.

\section{Conclusion}

We conclude that young TKD practitioners have better balance control than nonpractitioners. Less experienced TKD practitioners might rely more heavily on their visual and vestibular systems for balance whereas experienced practitioners rely more on the vestibular system. Further study should explore the longitudinal training effect of TKD so as to develop the evidence base for this exercise option to improve balance for adolescents.

\section{Acknowledgements}

The authors would like to acknowledge the Eastern Dragon Taekwondo Federation Hong Kong, the International Taekwondo Hong Kong Association and the Ching Ying Taekwondo Union for their assistance in recruiting Taekwondo subjects. This study was approved by the human subjects ethics review subcommittee of the Hong Kong Polytechnic University, Hong Kong (SAR), China. The authors have no financial affiliation (including research funding) or involvement with any commercial organization that has a direct financial interest in any matter included in this manuscript. The authors also have no other conflict of interest that is directly relevant to the content of this article.

\section{References}

1. Alpini, D., V. Mattei, H. Schlecht, and R. Kohen-Raz. Postural control modifications induced by synchronized ice skating. Sport Sci Health. 2:11-17, 2008.

2. Bringoux, L., L. Marin, V. Nougier, P.A. Barraud, and C. Raphel. Effects of gymnastics expertise on the perception of body orientation in the pitch dimension. J. Vestib. Res. 6:251-258, 2000.

3. Brudnak, M.A., D. Dundero, and F.M. Van Hecke. Are the 'hard' martial arts, such as the Korean martial art, Taekwon-Do, of benefit to senior citizens? Med. Hypotheses. 59:485-491, 2002.

4. Cromwell, R.L., P.M. Meyers, P.E. Meyers, and R.A. Newton. Tae Kwon Do: An effective exercise for improving balance and walking ability in older adults. J. Gerontol. 62A:641-646, 2007.

5. Del Percio, C., A. Brancucci, F. Bergami, et al. Cortical alpha rhythms are correlated with body sway during quite open-eyes standing in athletes: A high-resolution EEG study. Neuroimage. 36:822-829, 2007. 
6. Del Percio, C., C. Babiloni, N. Marzano, et al. "Neural efficiency" of athletes' brain for upright standing: A high-resolution EEG study. Brain Res. Bull. 79:193-200, 2009.

7. Fong, S.M., and G.Y. Ng. The effects of sensorimotor performance and balance with Tai Chi training. Arch. Phys. Med. Rehabil. 87:82-87, 2006.

8. Golomer, E., P. Dupui, P. Sereni, and H. Monod. The contribution of vision in dynamic spontaneous sways of male classical dancers according to student or professional level. J. Physiol. Paris. 93:233-237, 1999.

9. Herpin, G., G.C. Gauchard, A. Lion, P. Collet, D. Keller, and P.P. Perrin. Sensorimotor specificities in balance control of expert fencers and pistol shooters. J. Electromyogr. Kinesiol. 20:162-169, 2010.

10. Kazemi, M., J. Waalen, C. Morgan, et al. A profile of Olympic Taekwondo competitors. J Sports Sci Med. CSSI:114-121, 2006.

11. Lephart, S.M., J.L. Giraldo, P.A. Borsa, and F.H. Fu. Knee joint proprioception: A comparison between female intercollegiate gymnasts and controls. Knee Surg. Sports Traumatol. Arthrosc. 4:121-124, 1996.

12. Mesure, S., B. Amblard, and J. Cremieux. Effect of physical training on head-hip coordinated movements during unperturbed stance. Neuroreport. 8:3507-3512, 1997.

13. Nagy, E., K. Toth, G. Janositz, et al. Postural control in athletes participating in an ironman triathlon. Eur. J. Appl. Physiol. 92:407-413, 2004.

14. Nashner, L.M. Computerized dynamic posturography. In: Handbook of balance function and testing. G.P. Jacobson, C.W. Newman, and J.M. Kartush. St. Louis: Mosby Year book, 1997, pp. 261-307.

15. NeuroCom. Balance Manager Systems - Instructions for use. Oregon: NeuroCom International, Inc., 2008.

16. Paillard, T., F. Noe, T. Riviere, V. Marion, R. Montoya, and P. Dupui. Postural performance and strategy in the unipedal stance of soccer players at different levels of competition. J. Athl. Train. 41:172-176, 2006.

17. Park, Y.H., Y.H. Park, and J. Gerrard. Tae Kwon Do: the ultimate reference guide to the world's most popular martial art. London: Ward Lock, 1989.

18. Perrin, P., D. Schneider, D. Deviterne, C. Perrot, and L. Constantinescu. Training improves the adaptation to changing visual conditions in maintaining human posture control in a test of sinusoidal oscillation of the support. Neurosci. Lett. 245:155-158, 1998.

19. Perrot, C., D. Deviterne, and Ph. Perrin. Influence of training on postural and motor control in a combative sport. J Hum Mov Stud. 35:119-136, 1998.

20. Perrot, C., R. Moes, D. Deviterne, and P. Perrin. Postural adaptations during specific combative sport movements. Sci. Sports. 13:64-74, 1998.

21. Pieter, W. Martial Arts. In: Epidemiology of Pediatric Sports Injuries, D. Caine and N. Maffulli (Eds.). Basel: Karger, 2005, pp. 59-73.

22. Pieter, W., and J. Heijmans. Scientific Coaching for Olympic Taekwondo, 2nd ed. Aachen: Meyer and Meyer Sport, 2000.

23. Portney, L.G., and M.P. Watkins. Foundations of clinical research - Applications to practice, 3rd ed. New Jersey: Pearson Education, Inc., 2009.

24. Sadowski, J. Dominant Coordination Motor Abilities in Combat Sports. J Hum Kinetics. 13:61-72, 2005.

25. Suzana, M.A., and W. Pieter. Motor ability profile of junior and senior Taekwondo club athletes. BRJB. 3:325-331, 2009.

26. Tanguy, S., G. Quarck, O. Etard, A. Gauthier, and P. Denise. Vestibulo-ocular reflex and motion sickness in figure skaters. Eur. J. Appl. Physiol. 104:1031-1037, 2008.

27. Vecchio, F., C. Del Percio, N. Marzano, et al. Functional cortico-muscular coupling during upright standing in athletes and nonathletes: A coherence electroencephalographicelectromyographic study. Behav. Neurosci. 122:917-927, 2008.

28. Violan, M.A., E.W. Small, M.N. Zetaruk, and L.J. Micheli. The effect of karate training on flexibility, muscle strength, and balance in 8- to 13-year-old boys. Pediatr. Exerc. Sci. 9:55-64, 1997. 